\title{
Effect of thermal Gradient on the Thermomechanical Fatigue Behavior of Thermal Barrier Coating System
}

\author{
Feng HUANG ${ }^{1, a}$, Zhong-Jiao ZHOU ${ }^{2, b,{ }^{*}}, X^{4} \mathrm{HUA}^{3, c}$, Guo-Feng $\mathrm{CHEN}^{3, \mathrm{~d}}$, Xiao- \\ Zhou ZHOU ${ }^{4, e}$
}

\author{
${ }^{1}$ Guangdong Power Grid Co., Ltd., Electric Power Research Institute; Guangzhou 510080, China; \\ ${ }^{2}$ Division of Micro/Nano Manufacturing, State Key Laboratory ofTribology, Tsinghua University, \\ Beijing 100084, China \\ ${ }^{3}$ Corporate Technology, Siemens; Shanghai 200082, China; \\ ${ }^{4}$ Corporate Technology, Siemens; Beijing 100102, China; \\ ahuanfen777@126.com, bzjzhou10s@mail.tsinghua.edu.cn, cxu.hua@siemens.com, \\ dguofeng.chen@siemens.com, exiaozhou.zhou@siemens.com \\ *Corresponding author
}

Keywords: Ni-base superalloy, Thermal barrier coating, Thermomechanical fatigue, Thermal gradient, Stress

\begin{abstract}
As the key material of gas turbines used in elevated temperature, the mechanism of delamination and failure of thermal barrier coatings (TBCs) under service conditions has been the hot spot of research for a long time.The influence of thermal gradient on thermomechanical fatigue (TMF) behavior of TBCs structures was investigated in this paper. It was demonstrated that under the same strain range, the hollow samples with great thermal gradient experienced much lower maximum tensile stress than solid samples, thus leading to longer TMF lifetime than the solid samples. In solid samples, cracks were initiated in the thermally grown oxidation (TGO), and propagated along the TGO/ ceramic top coat, or propagated into the ceramic top coat, forming the delamination cracks. However, in hollow samples, radial stresses existed in the substrate and bond coat due to the thermal gradient during cooling. In addition, the thermal gradient accelerated $\mathrm{Al}$ diffusion from bond coat. These two factors weakened the bond coat and made the cracks propagate into the bond coat.
\end{abstract}

To achieve a higher working and energy efficiency of gas turbines, the inlet temperature elevates gradually from 900 to $1425^{\circ} \mathrm{C}$. The protective thermal barrier coatings (TBCs) get applied by overlaying the superalloy substrate due to their heat-insulation, anti-corrosion performance [1-3].

During service, the gas turbine blades endure high level dynamic mechanical stress as well as rapidly changing temperatures due to frequent startup and shutdown. The thermomechanical fatigue (TMF) is a major lifetime limiting factor, which causes the delamination of the ceramic top coat (TC) from the bond coat (BC) and the loss of the TBCs [4-7]. Additionally, to achieve higher cooling efficiency, the modern turbine blades are often in the form of thin wall structure [8-10], which means that large thermal gradient exists in the TBCs. Therefore, the TMF propertyconcerning thermal gradient is desperately needed to understand the failure behavior of TBCs under service conditions and to predict the lifetime of the components.

\section{Experiment}

In the present study, the columnar crystal superalloy MGA1400 was chosen as the substrate materials and was manufactured to solid TMF specimens and hollow ones concerning the thermal gradient according to Fig. 1. Then, all the substrates were grit blasted by alumina powder with 80 mesh grain size distribution. Afterwards, the substrate was deposited by High Velocity Oxygen Fuel (HVOF) with a CoNi32Cr32Al8Y0.5 alloy as the BC with the thickness between 80 and $100 \mu \mathrm{m}$. The 8 wt. \% 
$\mathrm{Y}_{2} \mathrm{O}_{3}$ partially stabilized $\mathrm{ZrO}_{2}$ (YSZ) ceramic TC was deposited by means of air plasma spraying (APS) with thickness between 300 and $320 \mu \mathrm{m}$, as shown in Fig. 2.
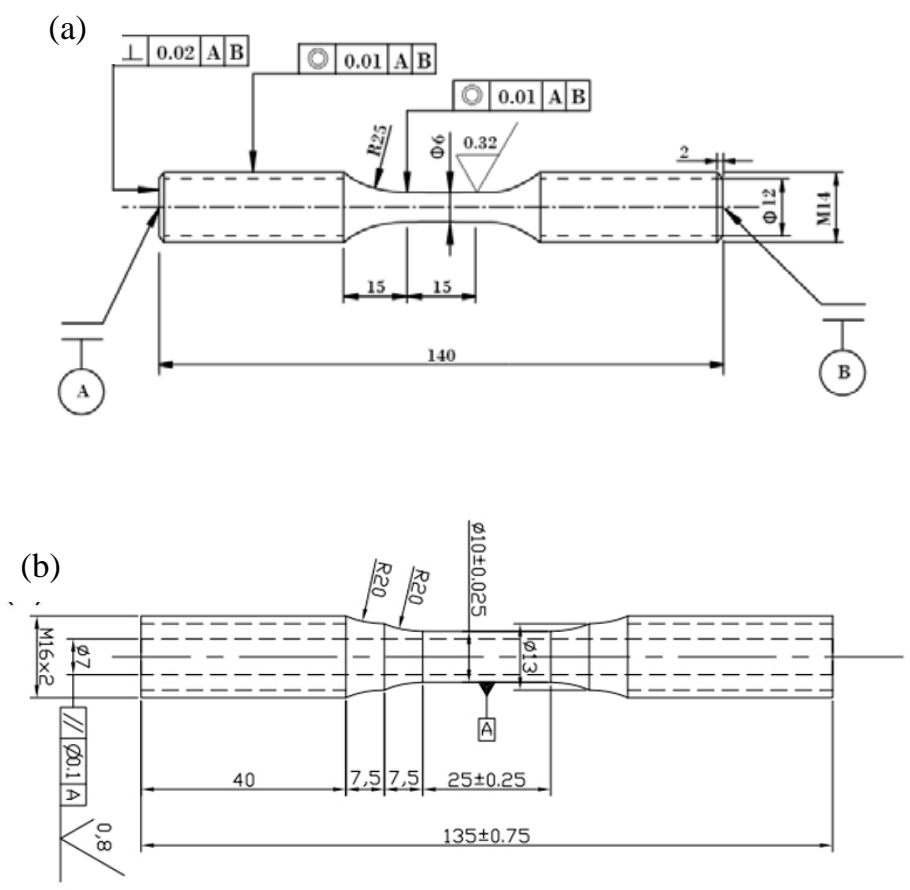

Fig. 1 The TMF specimen geometry (a) solid samples, (b) hollow samples.

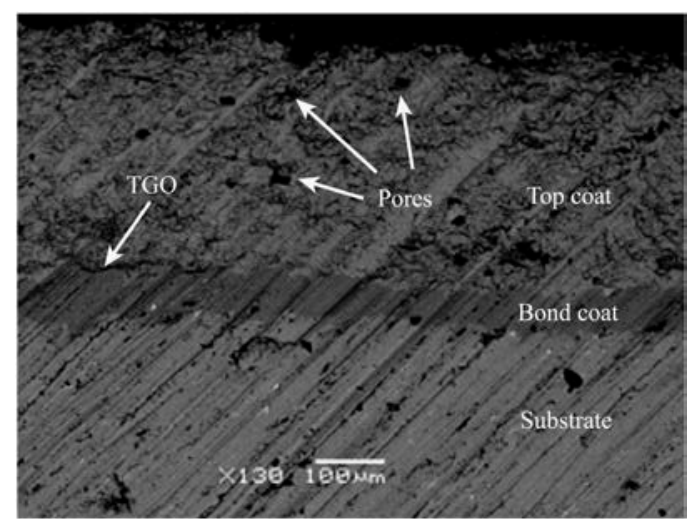

Fig. 2The microstructure of the as-deposited TBCs

The TMF tests were performed on an MTS810 closed-loop servo-hydraulic test machine with computer control. A radiation furnace powered by four cylindrical quartz lamps, each with amaximum power of $2.5 \mathrm{~kW}$ was used for heating [11]. Cooling was mainly achieved by thermal conduction into the water cooling specimen grips and forced by blowing compressed air. Besides these, internally compressed air cooling was used during the whole stage for hollow samples. Axial strain measurements were obtained using a self-supporting extensometer. Temperature control was conducted with a thermocouple enlaced in the middle of the gauge length.

In order to reduce the amount of experimental time and obtain TGO thickness close to actual service condition, all specimens were isothermally pre-oxidized at $1000^{\circ} \mathrm{C}$ in air for $100 \mathrm{~h}$ prior to the TMF experiments. To closely represent turbine engine service at high temperature, a dwelling time 5 min at the highest temperature was included in tests (Fig. 3).Four kinds of samples were used: sample 1 and 2 are solid samples with mechanical strain ranges $\Delta \varepsilon=-0.30 \%,-0.45 \%$, respectively, sample 3 and 4 are hollow samples with $\Delta \varepsilon=-0.30 \%,-0.45 \%$, respectively.To obtain a same temperature at TGO layer, the temperature range of $200-900^{\circ} \mathrm{C}$ and $300-1000^{\circ} \mathrm{C}$ are applied to the solid and hollow 
samples, respectively.After the TMF tests, the microstructure of the specimens were observed in details.

(a)

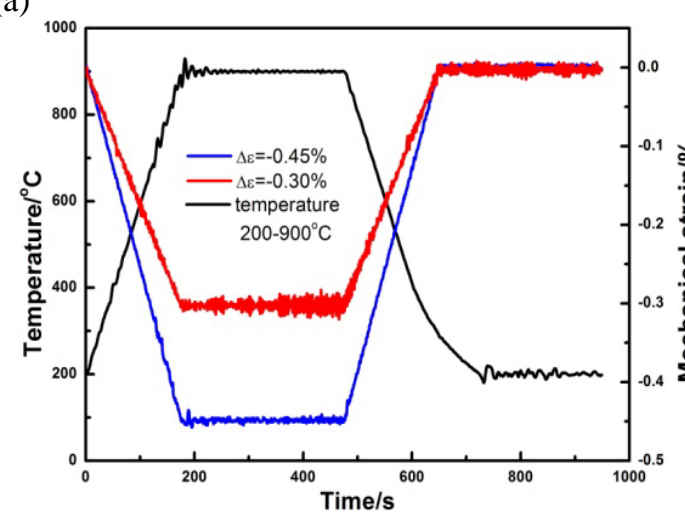

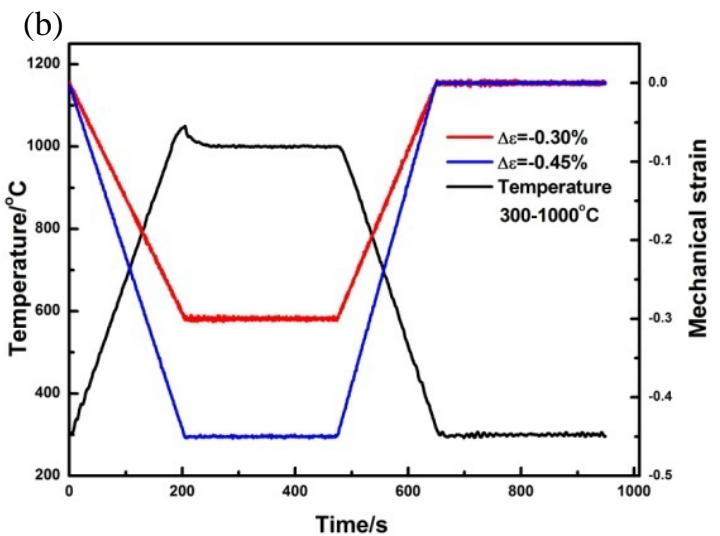

Fig.3 Loading curves of solid TMF samples (a) and hollow ones (b)

\section{Results and Discussion}

\subsection{The TMF Lifetime}

TBC spallation occurred after various numbers of cycles and the TMF lifetime(It means the number of cycles when TBCs spallation occurred)isdrawn in Fig. 4.It was shown that with the increase of strain ranges, TMF lifetime were reduced significantly. In addition, under the same strain range, the hollow samples had much longer lifetime than the solid samples. With $\Delta \varepsilon=-0.30 \%$,the TBC coating of solid samples got spalled after 65 cycles, while it turned to be 692 cycles for the hollow samples.

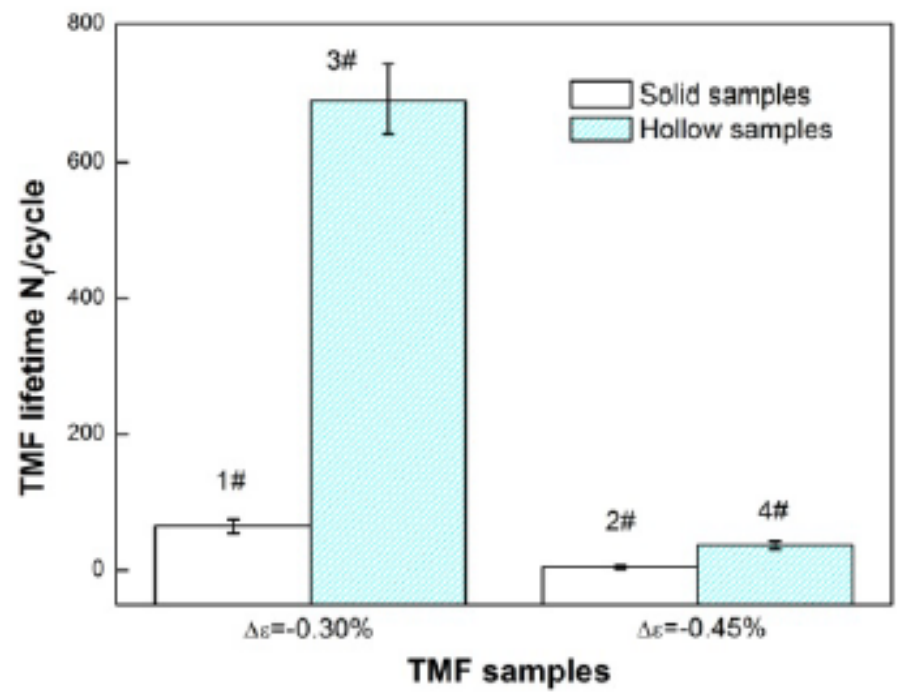

Fig. 4The TMF lifetime for sample 1-4

Fig. 5 shows the comparison of hysteresis loops of 1st cycle and half life cycle under various TMF tests. It was shown that the maximum compressive mechanical loading at maximum temperature led to severe inelastic compressive deformation during the 1st cycle. As for the solid samples, with increasing strain range from $-0.30 \%$ to $-0.45 \%$, the maximum tensile stresses increased from $100 \mathrm{MPa}$ to about $400 \mathrm{MPa}$ at 1st cycle. Afterwards, a cyclic shift of the stress response into the tensile regime occurred.However, the maximum tensile stresses of hollow samples at 1 st cycle was much lower, only about $120 \mathrm{MPa}$ when $\Delta \varepsilon=-0.45 \%$, which explained the much longer lifetime of hollow samples compared to solid samples. In addition, differently from the solid samples, no cyclic shift of the stress response into the tensile regime occurred. 

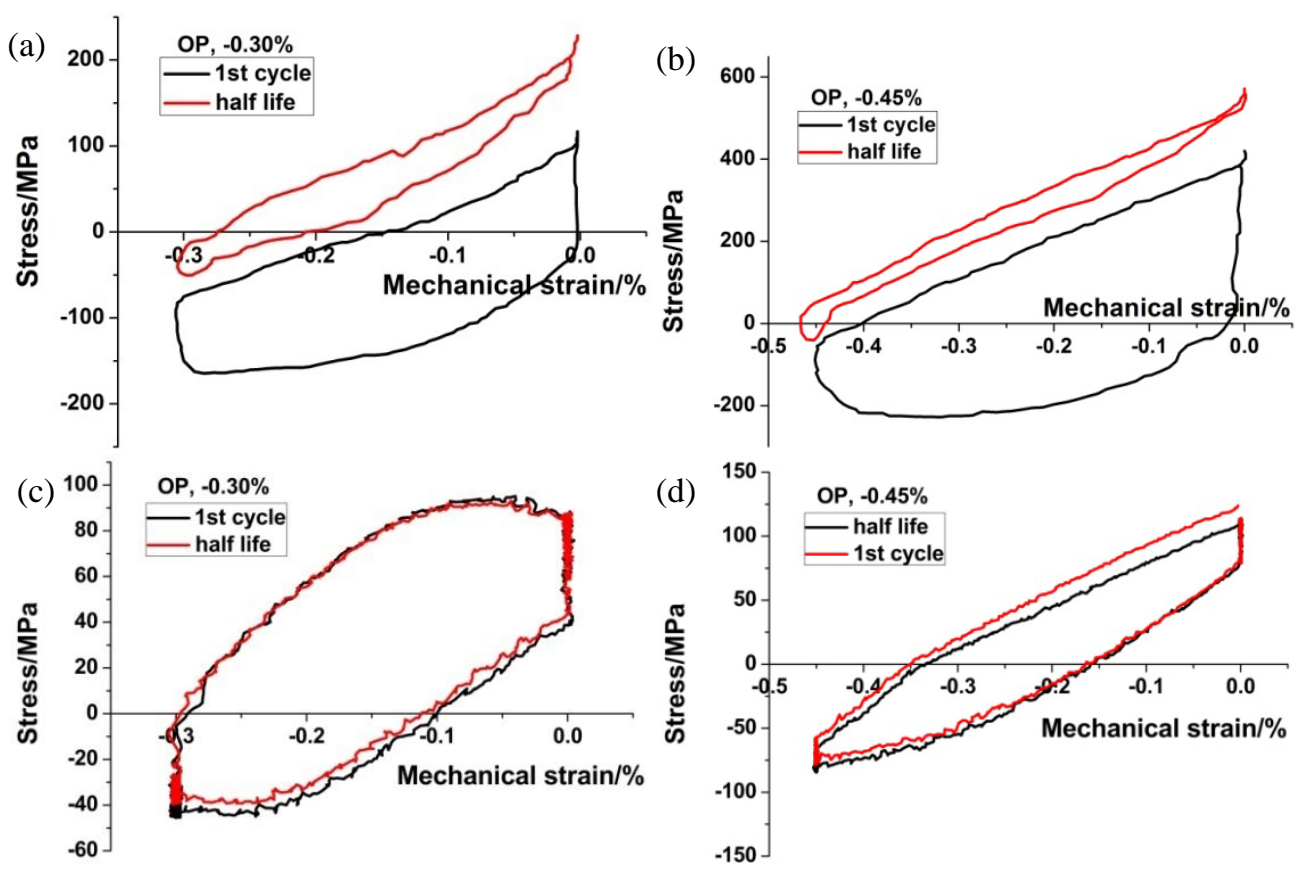

Fig. 5Hysteresis loops of 1st cycle and half life for solid and hollow samples. (a) Sample 1, (b)sample 2, (c) sample 3,(b) sample 4

The cyclic stress response behavior for solid and hollow samples at various mechanical strain ranges is shown in Fig. 6, which displays the variation of the maximum stress and the minimum stress with the number of the cycles. As for the solid samples, obviously the maximum stress gradually increased and the minimum stress decreased slightly with the increase of cycles. However, boththe maximum stress and the minimum stress kept stable during the whole cycles for hollow samples.
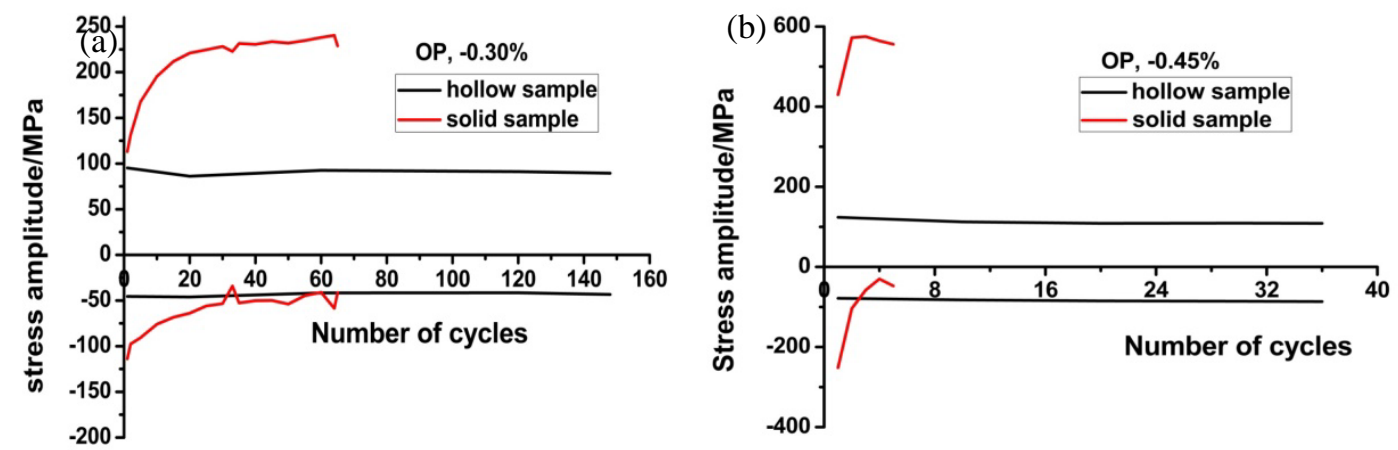

Fig. 6Comparison of Cyclic stress response curves for variousTMF and TGMF test. (a) OP, $\Delta \varepsilon=-$

$$
0.30 \% \text {, (b) OP, } \Delta \varepsilon=-0.45 \%
$$

\subsection{The TBC morphology after TMF Tests}

Typical cross-sections close to the spallation area are shown in Fig. 7. Obvious delamination cracks along the BC/TC interface and segmentation cracks in the TC could be seen in both solid and hollow samples. During cooling, due to the larger coefficient of thermal expansion of metal than that of TC layer, radial compressive stress in TC layer and circumferentially tensile stress at TC/TGO interface were formed $[12,13]$. As for the solid samples,cracks were initiated in TGO, and propagated along the TGO/ ceramic TC, or propagated into the ceramic TC due to its low resistance to thermal shock, forming the delamination cracks, as Fig. 7a,b showed. When the delamination cracks connected with the segmentation cracks in ceramic TC, the TBCs spalled.

However, as for the hollow samples, the substrate and bond coat can be considered as one layer neglecting the difference of coefficient of thermal expansion of these two parts.Due to the thermal 
gradient, the inner substrate would contract more severely than the $\mathrm{BC}$, thus leading to the radial compressive stresses formedat the $\mathrm{BC}$ layer during cooling [15, 16]. In addition, the thermal gradient accelerated $\mathrm{Al}$ diffusion from $\mathrm{BC}$ [17]. These two factors weakened the $\mathrm{BC}$ and made the cracks propagate into the $\mathrm{BC}$, just as shown in Fig. $7 \mathrm{c}$ and $\mathrm{d}$.
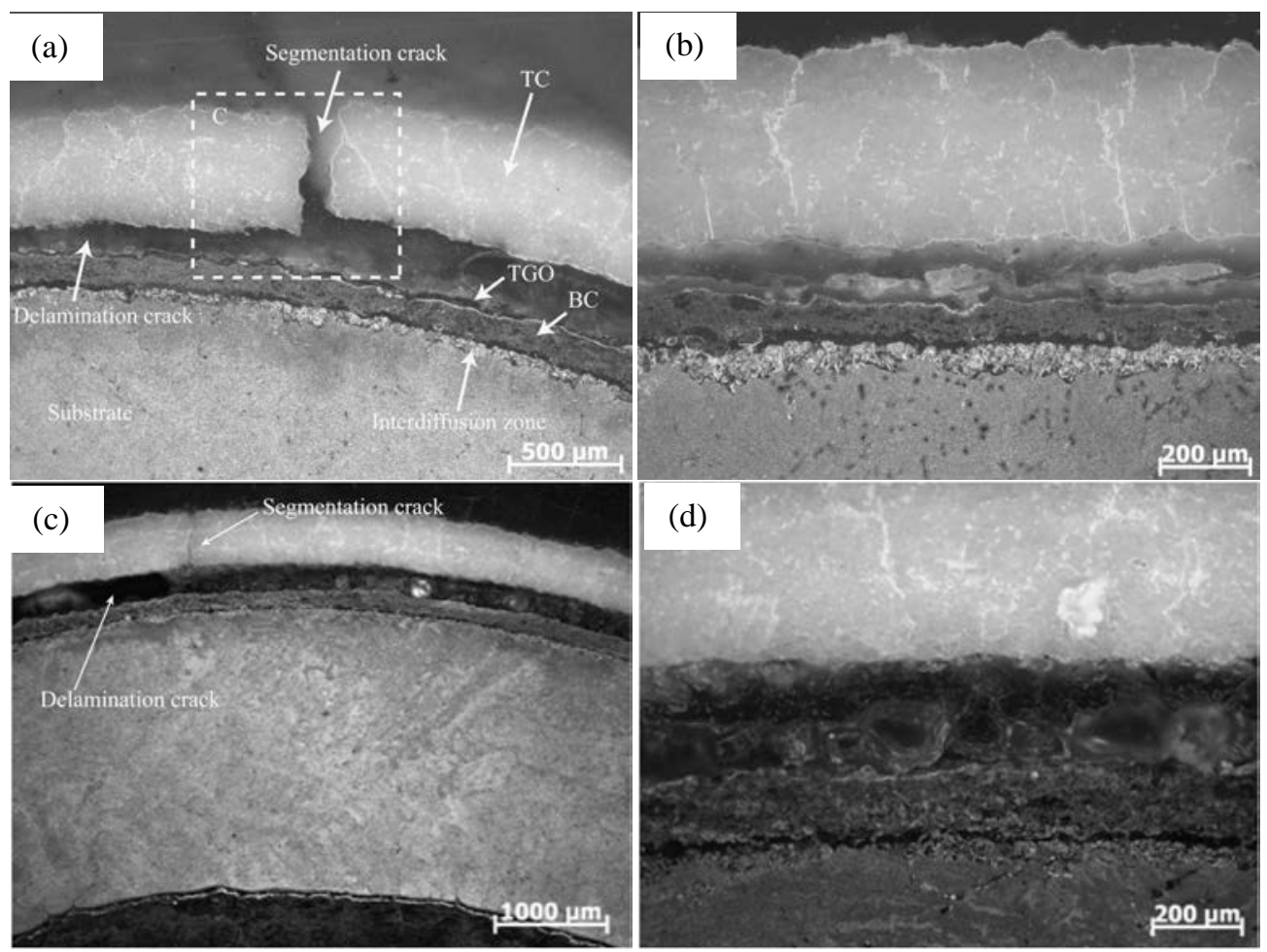

(d)

Fig. 7The TBC morphology after TMF tests. (a)(b) Solid samples with $\Delta \varepsilon=-0.30 \%$, (c)(d) hollow samples with $\Delta \varepsilon=-0.30 \%$

\section{Summary}

The influence of thermal gradient on the thermomechanical fatigue properties of Ni-based superalloy samples with thermal barrier coatings was investigated in this paper, several conclusions can be obtained:

(1) Under the same strain range, the hollow samples had much longer TMF lifetime than the solid samples.Both for solid and hollow samples, the TMF lifetime decreased with the increase of strain ranges.

(2) Under the same strain range, the maximum tensile stress of hollow samples at the1st cycle is much lower than that of solid samples.

(3) In solid samples, cracks were initiated in TGO, and propagated along the TGO/ ceramic TC, or propagated into the ceramic TC, forming the delamination cracks. However, as for the hollow samples, the thermal gradient resulted in radial stresses in the substrate and $\mathrm{BC}$ during cooling and accelerated $\mathrm{Al}$ diffusion from $\mathrm{BC}$, thus making the cracks propagate into the $\mathrm{BC}$.

\section{Acknowledge}

Present work was supported by the Research Program of China Southern Power Grid (KGD20140595).

\section{References}

[1] R.A. Miller, Current status of thermal barrier coatings-An overview, Surf. Coat. Tech. 1987, 30: 1-11 
[2] R.A. Miller, Thermal barrier coatings for aircraft engines: history and directions, J. Therm. Spray Tech. 1997, 6: 35-42

[3] Yujuan ZHANG, Xiaofeng SUN, Tao JIN, Nairen ZHAO, Hengrong GUAN, Zhuangqi HU, Microstructure of air plasma sprayed YSZ nanostructured thermal barrier coating, Acta Metall. Sin. 2003, 39(4): 395 (in Chinese)

[4] S. Kraft, R. Zauter, H. Mughrabi, Aspects of high-temperature low-cycle thermomechanical fatigue of a single crystal nickel-base superalloy, Fatigue Fract. Eng. M. 1993, 16: 237-253

[5] M. Bartsch, G. Marci, K. Mull, C. Sick, Lifetime prediction of ceramic thermal barrier coatings based on lifetime analyses of close to reality tests, Adv. Eng. Mater. 1999, 2: 127-129

[6] S. Pahlavanyali, A. Rayment, B. Roebuck, G. Drew, C. Rae, Thermo-mechanical fatigue testing of superalloys using miniature specimens, Int. J. Fatigue 2008, 30: 397-403

[7] E. Tzimas, H. Müllejans, S.D. Peteves, J. Bressers, W. Stamm, Failure of thermal barrier coating systems under cyclic thermomechanical loading, Acta Mater. 2000, 48: 4699-4707

[8] M. Bensch, E. Fleischmann, C.H. Konrad, Secondary creep of thin-walled specimens affected by oxidation, Superalloys 2012: 387

[9] R Hüttner, R Völkl, J Gabel, U. Glatzel, Creep Behavior of Thick and Thin Walled Structures of a Single Crystal Nickel-Base Superalloy at High Temperatures-Experimental Method and Results, Strain 2008, (1): 3

[10] A. Srivastava, S. Gopagoni, A. Needleman, V. Seetharaman, A. Staroselsky, R. Banerjee, Effect of specimen thickness on the creep response of a single crystal superalloy, Acta Mater.2012, 60 (16): 5697

[11] Z.B. Chen, Z.G. Wang, S.J. Zhu, Thermomechanical fatigue behavior of air plasma sprayed thermal barrier coating system, Mater. Sci. Eng. A2011, 528: 8396

[12] G. Kerkoff, R. Vaen, D. Stover, Numerically calculated oxidation induced stresses in thermal barrier coatings on cylindrical substrates, European Federation Corrosion Publications, 1999, 27: 373

[13] M. Ahrens, R. Vaen, G Kerkoff, D. Stöver, Life time prediction model for plasma-sprayed thermal barrier coatings based on a micromechanical approach, Ceramic materials and components for engines, 2007: 305-310

[14] J.M. Lee, H. Song, Y. Kim, J.M. Koo, C.S. Seok, Evaluation of thermal gradient mechanical fatigue characteristics of thermal barrier coating, considering the effects of thermally grown oxide, Int. J. Precis. Eng. Manuf.2015, 16(7): 1675-1679

[15] Y.C. Zhou, T. Hashida, Couple effects of temperature gradient and oxidation on thermal stress in thermal barrier coating system, Int. J. Solids Struct.2001, 38: 4235

[16] N. Ta, L.J. Zhang, Y. Tang, W.M. Chen, Y. Du, Effect of temperature gradient on microstructure evolution in Ni-Al-Cr bond coat/substrate systems: A phase-field study, Surf. Coat. Tech. 2015, 261: 364-374 